\title{
REGULATION AND INCENTIVES IN EUROPEAN AVIATION*
}

\author{
PHILIPPE GAGNEPAIN and PEDRO L. MARÍN \\ Universidad Carlos III de Madrid
}

\begin{abstract}
We study the effect of liberalization on costs and competition in the European airline industry. We construct and estimate a model that includes demand, capacity, and cost equations. The latter accounts for inefficiency and cost-reducing effort. We show that failure to account for the choice of effort would lead to biased estimates of efficiency and competition in the industry. We also find that the last European Union package of deregulatory measures has led to significant efficiency improvements and has fostered competition.
\end{abstract}

\section{INTRODUCTION}

$\mathrm{W}_{\mathrm{E}}$ E study the effect of liberalization on costs and competition in the European airline industry, accounting for inefficiency and cost-reducing effort. These are two ingredients that are usually excluded in empirical models of competition since, in general, firms are assumed to be efficient and observed costs to be exogenous. This is in contradiction to a long tradition of empirical literature related to the measurement of efficiency through the estimation of production and cost functions (see Kumbhakar and Lovell 2000). ${ }^{1}$ Moreover, recent literature on incentives and informational asymmetries accounts for the effect of cost-reducing actions of the firm, which sheds new light on costs endogeneity. The new theory of regulation suggests that the producer's endogenous effort closely depends on the constraints exerted by the regu-

* Both authors are members of the Center for Economic and Policy Research. We would like to thank Dennis W. Carlton, an anonymous referee, Lars-Hendrik Röller, Natalia Fabra, Jordi Jaumandreu, and Carmine Ornaghi as well as seminar participants at Universidad Carlos III and Universidad de Las Palmas for their comments. We would also like to thank Ana Baztán, Elena Sanjurjo, and Laura Sanjurjo for superb research assistance. Funding from the Fundación Ramón Areces is greatfully acknowledged.

${ }^{1}$ In particular, cost function specifications include an error term with two components independent of each other: a symmetric component that measures random variations of the frontier across firms and captures the effects of measurement error, other statistical noise, and random shocks outside the firm's control and a one-sided component that captures the effect of global inefficiency relative to the stochastic frontier.

[Journal of Law and Economics, vol. XLIX (April 2006)]

(C) 2006 by The University of Chicago. All rights reserved. 0022-2186/2006/4901-0009\$01.50 
latory environment that it faces (Laffont 1994). ${ }^{2}$ Inefficiency and cost-reducing effort are of particular importance when comparing industries subject to different incentives or analyzing changes in firms' behavior after a structural change in the rules governing the market. They can be expressed by taking into account the regulatory constraints impinging on the activity of each carrier. We are thus able to define a particular cost structure for each type of regulatory regime. According to our results, failure to account for the choice of effort would lead to biased estimates of efficiency and competition, ${ }^{3}$ which suggests that a proper modeling of the incentives provided by regulatory pressures allows a better evaluation of competitive forces.

The liberalization process of the European airline industry allows for a suitable application of this framework. At the beginning of the 1980s, European aviation was regulated by restrictive bilateral air service agreements between the countries concerned. Most routes were served by a duopoly operating under perfect collusion, and the industry was characterized by a lack of incentives to improve efficiency. This situation allowed firms, in many cases subsidized by their governments, to increase costs inefficiently.

Under the pressure of the U.S. Open Skies policy that started in 1978, several changes took place in the European market. First, in 1984-86, several governments started renegotiating their bilateral agreements to allow for entry and price reductions in a few international routes. ${ }^{4}$ Second, the European Community introduced three packages of measures in 1987, 1990, and 1992 that led to freedom to set frequencies, capacities, and prices and free entry by European carriers in any international European route. ${ }^{5}$ This process of gradual liberalization left the industry open to international competition, which introduced a significant variation in firms' incentives.

Simultaneously, European flag carriers got privatized, and explicit permission by the European Union (EU) authorities started to be necessary in order to receive any form of public subsidy. The new competitive pressure became the strongest incentive for carriers to reduce costs and improve efficiency. In addition, during the second half of the 1990s, European carriers

${ }^{2}$ Empirical works on this latter topic have not been numerous so far. See Dalen and GomezLobo (2003) and Gagnepain and Ivaldi (2002a, 2002b) for an analysis of alternative regulatory mechanisms applied to Norwegian and French urban transport networks.

${ }^{3}$ Several authors have attempted to account for cost endogeneity problems in the airline industry. Among them, Neven and Röller (1996) and Neven, Röller, and Zhang (2001) develop a competition model in which firms face workers' unions and market pressures that may affect operating costs. They apply this model to the European airline industry for the regulated period and show that the model that accounts for cost endogeneity supports a more competitive result than the standard one. In addition, $\mathrm{Ng}$ and Seabright (2001) use a panel of European and American carriers from 1982 to 1995 and a reduced-cost form in order to show that state ownership substantially leads to higher operating costs.

${ }^{4}$ Marín (1995) provides evidence for the effects of these liberal bilateral agreements on route-level competition.

${ }^{5}$ By April 1997, the same rules had to be applied to domestic routes within any EU country. 
organized themselves around code-sharing agreements and international alliances that emerged after long and complex processes of negotiation.

Using a nonnested procedure, we test several scenarios of incentive pressures against each other in order to identify the one that fits the data best. We show that cost-reducing effort has increased significantly only after the introduction of the last EU package of deregulatory measures in 1992, since the liberal bilateral agreements had limited effects and the 1987 package of deregulatory measures had no effect on firms' behavior.

The next section presents the cost, supply, and demand systems under consideration in the model. Section III focuses on the construction of the endogenous cost function, which depends on the state of the regulation. Functional forms, the estimation procedure, and the empirical results associated with the cost function are developed in Section IV. Section V is dedicated to the evaluation of competitive forces in the industry, which entails determining the pricing rules set by European carriers. Section VI concludes.

\section{Determining the Ingredients of the Model}

In what follows, we specify a model of airlines' behavior that encompasses situations of fully regulated as well as liberalized competitive markets. We are concerned with the effect of liberalization on market competition and firms' efficiency and the interconnection between these two factors. Accordingly, in the context of our model, airlines decide simultaneously about their cost-reducing effort and their pricing policy.

A modeling approach followed by several authors consists of assuming that firms make individual decisions for each route they serve (for the American domestic market, see Borenstein 1989, among others; for the European international market, see Marín 1995). This approach allows for route-specific policies. The advantage of this is that it takes into account route characteristics that may affect firms' behavior, such as the number and identity of the competitors, competitors' prices, or the length and density of the route. Such an approach would be useful for evaluating the effects of the different waves of deregulation on European firms' behavior in terms of costs reduction and pricing. In particular, note that the first wave of deregulation, namely, the liberal bilateral agreements, concerned some specific international routes only, as explained in the introduction.

In this paper, we use data at the firm level (Röller and Sickles 2000; Neven and Röller 1996; and Marín 1998, among others, use the same specification). Note that route-level data for European carriers are scarce. In particular, tickets prices at the route level are hardly available. This obliges us to use aggregate data for firms' cost and demand and consider that companies make corporate decisions that affect their entire network. We therefore test whether the different waves of European deregulation changed the decisions that firms 
make at the network level, but we do not try to identify which routes have been significantly affected. ${ }^{6}$

Note, moreover, that airlines serve a large number of interconnected routes that form a network. Sometimes consumers buy a company's service in one single route (what is known as a direct flight), but very often they buy sets of (normally two or three) interconnected routes (indirect flights through one or two hubs). In addition, when buying a ticket in an individual route, frequent consumers take into account the company's network size and characteristics since this affects the flexibility to make further interconnections if needed, exchange tickets, take alternative routes, and even enjoy frequent-flyer rewards and discounts. In other words, scope economies among routes and network effects (almost) impose a common policy on all the routes served by a given carrier. Our aim is to test whether the different waves of deregulation that affected the European market had a significant effect on the global cost-reducing behavior of carriers. Whether the operator should find appropriate and efficient solutions to solve potential conflicts, to improve the training of its employees, or to reorganize its productive structure are decisions that are worth considering at the network level.

\section{Costs}

In the short run, firms are endowed with a given technology that is determined by the quantity and quality of capital installed, as well as a network, determined by the history. In order to provide a given amount of service, $Q_{i}$, a carrier must buy variable inputs, namely, labor, $L_{i}$, and materials, $M_{i}$, the productivity of which depends on installed capital, $K_{i}$, and network exogenous characteristics, $z_{i}$. The production process and its underlying technology can be implemented through a short-run dual-cost function. Denoting by $w_{\mathrm{L}}$ and $w_{\mathrm{M}}$ the price of labor and materials, the program of the firm can be translated into the following terms:

$$
\begin{gathered}
\min _{L, M} C_{i}=\left(w_{\mathrm{L}} L+w_{\mathrm{M}} M\right) \exp (\theta-e), \\
\text { subject to } Q_{i}=Q\left(L_{i}, M_{i}, K_{i}, z_{i}, t ; \boldsymbol{\rho}\right),
\end{gathered}
$$

where $t$ is a trend and $\boldsymbol{\rho}$ is a vector of parameters denoting technology.

Note that $C_{i}$ are observed operating costs (which are different from efficient operating costs) and $\theta$ and $e$ denote firms' individual inefficiency and effort,

\footnotetext{
${ }^{6}$ If deregulation affects only some international routes instead of the whole network of a carrier, considering data at the carrier level may underevaluate the effects of deregulation on the carrier's behavior and lead to nonsignificant results. This is not the case in our paper since we obtain strongly significant effects for any wave of deregulation that we consider.
} 
two parameters that are unobservable. ${ }^{7}$ Thus, it is assumed that inefficiency prevents the firm from reaching the required output level $Q_{i}$ at the minimum cost. Cost-reducing effort can be undertaken by managers to counterbalance the effect of inefficiency. For instance, managers may spend time and effort in improving the location of inputs within the network, monitoring employees, solving potential conflicts, and so on. The associated short-run cost function, conditional on capital installed, inefficiency, and effort is

$$
C_{i}=C\left(Q_{i}, \omega_{i}, K_{i}, z_{i}, \theta_{i}, e_{i} ; \beta\right),
$$

where $\beta$ is a vector of parameters to be estimated. Assume moreover that cost-reducing effort involves some internal cost or disutility that can be represented through a convex function $\Psi\left(e_{i} ; \mu\right)$. Cost-reducing effort is endogenous and depends on the regulatory constraint impinging on the activity of the airline carrier.

\section{Capacity}

Before moving on to the demand side, we should notice that in transportation industries, costs and revenues are driven by two different measures of output. Costs are determined by capacity supplied, namely, available seatkilometers, which, in turn, depends on fleet capacity (measured by the number of seats available) and total kilometers flown by the airplanes. However, available seat-kilometers are only an intermediate output that is used by consumers to produce the final output, revenue passenger-kilometers (see Berechman 1993). This final output, $q_{i}$, determines carriers' revenues. Still, capacity and demand are closely related by a function that may change with time, $t$, and with the technology available,

$$
Q_{i}=\Phi\left(q_{i}, t ; \lambda\right),
$$

where $\lambda$ is a vector of parameters.

\section{Demand}

On the demand side, firm $i$ 's demand depends on its own price and its competitors' price, $p_{i}$ and $p_{j}$, respectively, as well as market-exogenous characteristics, $m_{i}$. A limited number of competitors meet on each route, with the combination of competitors changing from one route to another. Different competitors supply alternative products that differ in time schedule, number of stops, availability of interconnections with other flights, and so on. Ac-

\footnotetext{
${ }^{7}$ It might be useful to note at this stage that the inefficiency term $\theta$ should be viewed as a measure of relative inefficiency rather than absolute inefficiency. A measure of absolute inefficiency includes a component that can be explained by exogenous factors that may be captured by various explanatory variables (for instance, the size of the network and the average stage length defined in the following sections). Hence, the parameter $\theta$ should be considered the unobservable part of the absolute inefficiency, not captured by the explanatory variables.
} 
cordingly, the services offered by different airlines can be regarded as imperfect substitutes. Actually, a small set of competitors meet in each individual market. By assuming the same cost-reducing effort and pricing policy for all the routes served by one company, we are implicitly saying that $p_{j}$ represents the average price requested by the different competitors that firm $i$ meets in the routes it serves. Accordingly, each carrier faces a demand of the form

$$
q_{i}\left(p_{i}, p_{j}, m_{i}, t ; \boldsymbol{\alpha}\right), \quad i=1, \ldots, N,
$$

where $\alpha$ is a vector of parameters.

Next, we need to define the structure of the system made of equations (1)-(3). This entails describing carefully the decisions made by the airline carriers, namely, cost-reducing effort and pricing. Before entering into the analysis, it is worth a reminder that the pricing structure is independent of the nature of the regulatory pressures impinging on the activity of the firm. ${ }^{8}$ For this reason, incentive effects and pricing by firms can be presented separately. Although prices and effort are determined simultaneously in the decision process, we choose such an approach for ease of exposition.

\section{Regulatory Rules and Costs}

This section focuses on the construction of the structural cost function. During the second half of the 1980s, the European airline industry switched from bilateral air service agreements to more competitive markets. This might have influenced cost-reducing activities. We propose to account for these regulatory pressures through the cost function (1) that is conditional on the cost-reducing parameter $e$. Deriving the equilibrium level of $e$ and plugging it back into the primal cost expression allows us to account for endogenous effort and derive a structural cost form that can be estimated. The aim of such an approach is twofold. First, different scenarios associated with the different waves of market deregulation can be tested against each other in order to figure out what measures had significant effects on the behavior of European airline carriers in terms of cost reduction. Second, accounting for changes in regulation through the cost structure enables us to reduce the source of mispecification, which, in turn, should avoid bias in the estimation of the technological parameters. This will allow us to assess in a more satisfactory way the effect of regulatory constraints on the degree of competition of the industry.

Any firm that is a residual claimant for cost savings is willing to provide effort $e$ in order to reduce its operating costs, $C_{i}$, in a significant manner.

\footnotetext{
${ }^{8}$ The particular structure we use to incorporate technical inefficiency and effort parameters allows the incentive-pricing dichotomy principle to hold. See Laffont and Tirole (1993). It means that the same pricing formula applies whether we assume strong or soft regulatory pressures.
} 
Since the cost reduction activity is costly, the firm sets the optimal effort level $e$ that maximizes its profit $\pi_{i}$. Denoting by $p_{i}$ the price of the service to be sold, the profit is simply defined as the difference between revenue $R_{i}=q_{i}(\cdot) p_{i}$ and total cost TC $=C_{i}\left(e_{i}, \cdot\right)+\Psi\left(e_{i}, \cdot\right)$. The program of the firm is

$$
\max _{e} \pi_{i}=q_{i}(\cdot) p_{i}-C_{i}\left(\Phi\left(q_{i}(\cdot), \cdot\right), \omega_{i}, K_{i}, z_{i}, \theta_{i}, e_{i}\right)-\Psi\left(e_{i}\right) .
$$

Note that since revenue $R_{i}$ is independent of effort $e$, this program is equivalent to the one in which the firm sets the optimal effort level $e$ that minimizes TC. The first-order condition of this program is

$$
-\frac{\partial C_{i}}{\partial e_{i}}\left(\Phi\left(q_{i}(\cdot), \cdot\right), \omega_{i}, K_{i}, z_{i}, \theta_{i}, e_{i}\right)=\Psi^{\prime}\left(e_{i}\right),
$$

which implies that the optimal effort level equalizes marginal cost savings and the marginal disutility of effort.

On the other hand, a firm that is not a residual claimant for cost reductions has no incentives to provide costly effort. Therefore the optimal effort of a nonresidual claimant firm is supposed to be equal to zero.

Before deregulation, European airline carriers were mainly public entities regulated by bilateral service agreements. Subsidies would generally allow these firms to completely cover costs. It is therefore assumed that before deregulation, any operator would behave as a nonresidual claimant firm and would not provide any effort at all. Denote by $e^{\mathrm{R}}$ such an effort level. After deregulation, as already mentioned, the new competitive pressure and the abandonment of subsidizing practices would provide the operating firms with perfect incentives for cost and inefficiency reduction. We consider then that the optimal effort provided by a deregulated firm is given by the condition (5) and is denoted as $e^{\mathrm{D}}$. Given these two effort levels, we can write the cost function as

$$
C^{s}\left(\Phi\left(q_{i}(\cdot), \cdot\right), \omega_{i}, K_{i}, z_{i}, \theta_{i}, e^{s}\right),
$$

where $s$ denotes the regulatory regime, which can be either regulation, R, or deregulation, D.

\section{Testing the Effects of Liberalization on Costs}

The next step consists in proposing specific functional forms for the cost and demand functions, as well as the cost-reducing effort and the relationship between demand and supply, in order to derive a set of structural equations to be estimated. Using data on the European airline carriers before and after the different waves of liberalization, we are capable of shedding light on the cost structure that fits reality the best, namely, figuring out which package 
of deregulation had a significant effect on firms' behavior. ${ }^{9}$ This section presents the empirical model and the estimation results.

\section{Empirical Implementation}

We assume a Cobb-Douglas specification for the cost function in (1). This specification retains the main properties desirable for a cost function and provides a sufficiently precise description of the technology, while remaining tractable for our purpose (for details on the same choice for the airline industry, see Marín 1998). Alternative, more flexible, specifications such as the translog function lead to cumbersome computations of the first-order conditions when effort is unobserved. ${ }^{10}$ The cost function is then specified as

$$
C_{i}=\beta_{0} \omega_{L i}^{\beta_{1}} \omega_{M i}^{\beta_{2}} Q_{i}^{\beta_{3}} K_{i}^{\beta_{4}} z_{i} \exp \left(\beta_{t} t+\theta_{i}-e_{i}+u_{c i}\right),
$$

where $\omega_{L i}, \omega_{M i}, K_{i}$, and $z_{i}$ denote wages, price of materials, capital installed, and network exogenous characteristics that affect the cost function and $t$ is a trend. In addition, $e_{i}$ represents effort, $\theta_{i}$ is the inefficiency term, and $u_{c i}$ is an error term. Note that $\theta$ is characterized by a density function $f(\theta)$ defined over an interval $\left[\theta_{\mathrm{L}}, \theta_{\mathrm{U}}\right]$, where $\theta_{\mathrm{L}}$ and $\theta_{\mathrm{U}}$ denote the most efficient and inefficient firms, respectively

For our empirical specification, we assume that $z_{i}$ includes measures of airlines' network size, $\mathrm{NET}_{i}$, and average stage length, $\mathrm{ASL}_{i}$ (on the introduction of these two variables in the cost function and their effects on airlines' productivity, see Marín 1998; Neven, Röller, and Zhang 2001) ${ }^{11}$ and has the following shape:

$$
z_{i}=\mathrm{NET}_{i}^{\beta_{5}} \times \mathrm{ASL}_{i}^{\beta_{6}} .
$$

With respect to the internal cost of effort and the relationship between demand, $q_{i}$, and supply, $Q_{i}$, represented in (2), we assume the following functional forms: ${ }^{12}$

$$
\Psi\left(e_{i}\right)=\exp \left(\mu e_{i}\right)-1, \mu>0
$$

and

$$
Q_{i}=\lambda_{0} q_{i}^{\lambda_{1}} \exp \left(\lambda_{t} t+u_{Q i}\right),
$$

respectively, where $u_{Q i}$ is an error term.

\footnotetext{
${ }^{9}$ See the Appendix for a detailed description of the data and the construction of the variables.

${ }^{10}$ In particular, in order to solve for equation (13) below, plug it into equations (15) and (17), and estimate equation (17) applying parametric techniques, we need a Cobb-Douglas specification.

${ }^{11} \mathrm{~A}$ measure of airport concentration was included in an alternative specification, but it turned out to be highly correlated with the size of the network.

${ }^{12}$ Notice that $\Psi\left(e_{i}\right)$ is a convex function, with $\Psi(0)=0, \Psi^{\prime}\left(e_{i}\right)>0$, and $\Psi^{\prime \prime}\left(e_{i}\right)>0$.
} 
The demand equation corresponding to (3) is specified in linear form as follows:

$$
q_{i}=\alpha_{0}+\alpha_{1} p_{i}+\alpha_{2} p_{j}+\alpha_{3} \mathrm{GCONS}_{i}+\alpha_{t} t+u_{q i},
$$

where $p_{i}$ represents firm $i$ 's weighted average price, which is calculated as passenger revenues over passenger-kilometers flown, $\mathrm{GCONS}_{i}$ is consumption growth in its home country, as a measure of economic activity, ${ }^{13} p_{j}$ is an index of the passenger revenues over passenger-kilometers flown of all other airlines, $t$ is a time trend, and $u_{q i}$ is an error term.

Now, using the functional forms for operating cost (7), internal cost of effort (9), and the first-order condition (5) on effort activity, we are able to express the effort level under both regulation and deregulation periods. Note that the first-order condition regarding optimal effort under deregulation $e^{\mathrm{D}}$ can now be written as

$$
C_{i}(\cdot)=\mu \exp \left(\mu e_{i}^{\mathrm{D}}\right) .
$$

Substituting (7) and (9) into (12), we can solve for $e^{\mathrm{D}}$ as

$$
\begin{aligned}
e_{i}^{\mathrm{D}}= & \frac{1}{\mu+1}\left(\ln \beta_{0}+\beta_{1} \ln Q_{i}+\beta_{2} \ln \omega_{L i}+\beta_{3} \ln \omega_{M i}+\beta_{4} \ln K_{i}\right. \\
& \left.+\beta_{5} \ln \mathrm{NET}_{i}+\beta_{6} \ln \mathrm{ASL}_{i}+\theta-\ln \mu+u_{c i}\right),
\end{aligned}
$$

while

$$
e_{i}^{\mathrm{R}}=0 .
$$

As predicted by the new theory of regulation, the effort level of the residual claimant firm increases with $\theta$; namely, a more inefficient carrier needs to be more active in cost-reducing activities than a less inefficient one in order to reach the same cost level. Note, moreover, that these carriers are willing to provide lower effort levels when effort is more costly (the cost-reducing technology parameter $\mu$ is greater). Substituting $e^{\mathrm{D}}$ and $e^{\mathrm{R}}$ back into the primal cost structure (7) allows us to obtain the final forms to be estimated: $C^{\mathrm{R}}(\cdot)$ and $C^{\mathrm{D}}(\cdot)$. We therefore obtain

$$
C_{i}^{\mathrm{D}}=c_{0} \omega_{L i}^{\beta_{1}^{\prime}} \omega_{M i}^{\beta_{2}^{\prime}} Q_{i}^{\beta_{3}^{\prime}} K_{i}^{\beta_{4}^{\prime}} \mathrm{NET}_{i}^{\beta_{5}^{\prime}} \operatorname{ASL}_{i}^{\beta_{6}^{\prime}} \exp \zeta\left(\beta_{t} t+\theta_{i}+u_{c i}^{\prime}\right)
$$

and

$$
C_{i}^{\mathrm{R}}=\beta_{0} \omega_{L i}^{\beta_{1}} \omega_{M i}^{\beta_{2}} Q_{i}^{\beta_{3}} K_{i}^{\beta_{4}} \mathrm{NET}_{i}^{\beta_{5}} \operatorname{ASL}_{i}^{\beta_{6}} \exp \left(\beta_{t} t+\theta_{i}+u_{c i}\right),
$$

where $\zeta=\mu /(1+\mu), \quad c_{0}=\exp \left\{\ln \beta_{0}+[1 /(1+\mu)]\left(\ln \mu-\ln \beta_{0}\right)\right\}, \quad \beta_{k}^{\prime}=$ $\zeta \beta_{k}$, and $u_{c i}^{\prime}=\zeta u_{c i}$. Notice that $\beta_{k}^{\prime} \rightarrow \beta_{k}$ as $\mu \rightarrow+\infty$. In words, as the cost of

\footnotetext{
${ }^{13}$ Some alternative measures of economic activity were included in this expression either with or without GCONS. The inclusion of several variables led to multicolinearity problems. When only one of the variables was included, none provided a better fit than GCONS. Accordingly, we decided to drop alternative variables and leave only GCONS.
} 
effort grows, the effort level falls and expression (15) converges to (16). This implies that if effort is not taken into account, the estimates of the elasticities will be biased.

The cost function to be estimated is then

$$
\begin{aligned}
C_{i}= & \xi_{i}^{\mathrm{D}}\left[c_{0} \omega_{L i}^{\beta_{1}^{\prime}} \omega_{M i}^{\beta_{2}^{\prime}} Q_{i}^{\beta_{3}^{\prime}} K_{i}^{\beta_{4}^{\prime}} \mathrm{NET}_{i}^{\beta_{5}^{\prime}} \operatorname{ASL}_{i}^{\beta_{6}^{\prime}} \exp \zeta\left(\beta_{t} t+\theta_{i}+u_{c i}^{\prime}\right)\right] \\
& +\xi_{i}^{\mathrm{R}}\left[\beta_{0} \omega_{L i}^{\beta_{1}} \omega_{M i}^{\beta_{2}} Q_{i}^{\beta_{3}} K_{i}^{\beta_{4}} \mathrm{NET}_{i}^{\beta_{5}} \mathrm{ASL}_{i}^{\beta_{6}} \exp \left(\beta_{t} t+\theta_{i}+u_{c i}\right)\right],
\end{aligned}
$$

where $\xi_{i}^{\mathrm{D}}$ takes value of one if the firm operates in a deregulated industry and zero otherwise, while $\xi_{i}^{\mathrm{R}}$ takes value of one if the firm operates in a regulated industry and zero otherwise. In the course of the estimation, several vectors $\xi_{i}^{\mathrm{D}}$ and $\xi_{i}^{\mathrm{R}}$ will be assumed depending on the nature of the various deregulatory measures introduced in the European airlines market, and their results will be tested against each other in order to unravel their effects on competition.

The system of equations formed by (10), (11), and (17) is determined simultaneously. Accordingly, and in order to avoid endogeneity problems, these equations are estimated by the instrumental variables estimation method. The cost function (17) includes a nonobservable parameter, namely, $\theta$, characterized by a half-normal density function $f(\theta) .{ }^{14}$ When estimating this cost function, one needs to compute the integral of the joint density function of $\theta$ and $u_{c i}$ over $[0, \infty]$ (for more details, see Kumbhakar and Lovell 2000). Note that the system is identified and all parameters can be recovered, given that by homogeneity of degree 1 in input prices, $\beta_{1}+\beta_{2}=1$.

\section{Estimation Results}

Tables 1-6 provide the results for the econometric model. We emphasize in this section the two main arguments that are discussed in this paper. First, depending on how deregulation is interpreted, different cost structures can be estimated. Then a nonnested test helps us to choose the best cost structure in the sense that it is the one that fits the data the best.

Table 1 presents the results for the demand equation. The coefficients of all the variables are significant and have the expected sign. From our estimates, own-price and cross-price demand elasticities of the average carrier are $\eta_{i i}=-2.243$ and $\eta_{i j}=2.114$, respectively, which is in line with the

\footnotetext{
${ }^{14}$ The distribution of firms' global inefficiency will be truncated from above if the most inefficient firms exit the industry. However, given that global inefficiency is formed by two components, namely, inefficiency beyond the control of the firm, $\theta$, and cost-reducing effort, $e$, this does not lead necessarily to a truncated distribution of $\theta$; that is, a firm with a high $\theta$ could survive if it sets a high level of $e$, while a competitor with a lower $\theta$ and a lower $e$ could exit. In addition, note that within the set of European carriers included in the study, we do not observe any exit. First, this was not possible during the regulated period because public subsidies ensured the balance of flag public carriers' budgets. Second, we observe only the first 7 years following liberalization before any firm decided to exit.
} 
TABLE 1

Demand Function: Instrumental Variables Estimation Method (Dependent Variable: $q_{i}$ )

\begin{tabular}{lccc}
\hline \hline Variable & Coefficient & Estimate & SD \\
\hline Constant & $\alpha_{0}$ & .01 & .01 \\
$p_{i}$ & $\alpha_{1}$ & -3.55 & -3.55 \\
$p_{j}$ & $\alpha_{2}$ & 4.52 & 4.52 \\
GCONS $_{i}$ & $\alpha_{3}$ & .0005 & .0005 \\
$T$ & $\alpha_{t}$ & .01 & .01 \\
\hline
\end{tabular}

NotE. $-\mathrm{SD}$ of the error term $=.12(.01) ; R^{2}=.76$.

TABLE 2

Demand-CAPACITy Relationship: InStrumental Variables Estimation Method (Dependent Variable: $\ln \left(Q_{i}\right)$ )

\begin{tabular}{lccc}
\hline \hline Variable & Coefficient & Estimate & SD \\
\hline Constant & $\lambda_{0}$ & 5.31 & .78 \\
$\ln \left(q_{i}\right)$ & $\lambda_{1}$ & .68 & .05 \\
$t$ & $\lambda_{t}$ & .05 & .01 \\
\hline
\end{tabular}

NOTE. $-\mathrm{SD}$ of the error term $=.45(.03) ; R^{2}=.67$.

results reported in previous studies of the airline industry. ${ }^{15}$ Table 2 presents the demand-capacity relationship. Again, the coefficients are significant and have the expected sign. In both cases, the overall fit of the regression is satisfactory. The main interest of these two equations is to provide instruments for capacity and demand.

Tables 3 and 4 present the estimates for the cost function as well as the effort disutility parameters, obtained from the estimation of equation (17). (Vuong tests for alternative scenarios are presented in Table 5.) In order to test the effect of liberalization, this equation is estimated under alternative scenarios related to the deregulatory packages introduced by the EU and the liberal bilateral agreements signed by the United Kingdom with other countries. In all cases but scenario 1 , we include the term $\theta$ to measure inefficiency. In addition, the following distinctions are made: scenario 1 is a model with no effort and no inefficiency term, in scenario 2 firms do not make any effort to reduce inefficiency after the introduction of deregulatory measuresnamely, the effect of deregulation is not accounted for, in scenario 3 deregulation affects firms' behavior after the third EU package of measures in 1992, and scenario 4 deregulation affects the behavior of the firms affected

\footnotetext{
${ }^{15}$ A survey by Oum, Waters, and Yong (1992) on price elasticities of air transport demand suggests that empirical findings obtained during the 1980 s usually lie betwen -.4 and -4.51 . A fairly elastic demand in the European airline industry should not be a surprise since our database includes price-sensitive holiday markets.
} 
TABLE 3

Cost Function: Instrumental Variables Estimation Method (Dependent Variable: $\ln \left(C_{i}^{*}\right)$ )

\begin{tabular}{|c|c|c|c|c|c|c|}
\hline Variable & Coefficient & Scenario 1 & Scenario 2 & Scenario 3 & Scenario 4 & Scenario $3^{\prime \prime}$ \\
\hline Constant & $\beta_{0}$ & $1.095(.724)$ & $-.090(.411)$ & .049 (1.013) & $-.292(.747)$ & $-.276(.637)$ \\
\hline$w_{L i}$ & $\beta_{1}$ & $.437(.065)$ & $.393(.037)$ & $.318(.071)$ & $.375(.076)$ & $.326(.073)$ \\
\hline$Q_{i}$ & $\beta_{3}$ & $.864(.065)$ & $.933(.063)$ & $1.009(.067)$ & $1.028(.060)$ & $1.051(.057)$ \\
\hline $\mathrm{NET}_{i}$ & $\beta_{5}$ & $-.242(.084)$ & $-.228(.088)$ & $-.360(.079)$ & $-.368(.078)$ & $-.398(.074)$ \\
\hline $\mathrm{ASL}_{i}$ & $\beta_{6}$ & $-.400(.088)$ & $-.381(.053)$ & $-.422(.097)$ & $-.345(.083)$ & $-.405(.101)$ \\
\hline$T$ & $\beta_{t}$ & $.071(.040)$ & $.068(.032)$ & $.271(.057)$ & $.097(.040)$ & $.269(.061)$ \\
\hline$e_{i}$ & $\ln (\mu)$ & $\ldots$ & & $3.754(.214)$ & $5.088(.821)$ & $3.969(.256)$ \\
\hline SD of $\theta$ & & $\ldots$ & $.474(.036)$ & $.270(.077)$ & .404 (.069) & $.313(.054)$ \\
\hline SD of error term & & $.257(.015)$ & $.023(.026)$ & $.164(.040)$ & $.098(.057)$ & $.121(.054)$ \\
\hline$R^{2}$ & & .87 & & & & \\
\hline Vuong test & & 3.121 & 2.777 & & 1.996 & \\
\hline
\end{tabular}

NotE. - Standard deviations are in parentheses. Values for the Vuong test below -2 favor the alternative scenario against scenario 3 , and those above 2 favor scenario 3 against the alternative scenario. Scenarios: (1) deregulation has no effect $\left(e_{i}=0\right)$, and the model does not account for one-sided inefficiency $\left(\theta_{i}=0\right)$, (2) deregulation has no effect, (3) deregulation affects firms' behavior after 1992, (4) deregulation affects firms' behavior after 1985 for British Airways, KLM, Lufthansa, and after 1992 for the remaining companies, and $\left(3^{\prime \prime}\right)$ same as scenario 3 but dropping the observations for the last 2 years (1998-99). Note that scenarios $3^{\prime \prime}$ and 3 cannot be tested against each other since they consider two samples of different sizes. In all scenarios but 1 the model accounts for one-sided inefficiency term $\left(\theta_{i} \geq 0\right)$.

by the introduction of liberal bilateral agreements, British Airways, KLM, Lufthansa, and Sabena after 1985 and the remaining companies in $1993 .{ }^{16}$ The comparison of scenarios 3 and 4 allows us to identify whether the liberal bilateral agreements have any effect on firms' behavior.

In addition, in order to test whether the EU deregulatory measures started having an effect in 1987, after the introduction of the first package of measures, we also try two alternative scenarios: scenario $3^{\prime}$, in which deregulation affects firms' behavior after the first EU package of measures in 1987, and scenario 4 ', in which deregulation affects the behavior of the firms affected by the introduction of liberal bilateral agreements after 1985 and the remaining companies in 1987. Finally, given that some new competitors such as easyJet and Virgin, not included in the sample, started operating a significant number of international European routes during the period 1997-99 and that this could bias our measure of rivals' prices, we construct scenario $3^{\prime \prime}$, which is recovered from scenario 3 after having excluded the last 2 years of observations, 1998 and 1999.

The variable capital has been dropped from the regressions because the correlation coefficient between output and capital is .91, which causes mul-

${ }^{16}$ Scenario 4, with British Airways, KLM, and Lufthansa changing behavior after the introduction of liberal bilateral agreements in 1985, has been chosen among different sensible combinations of firms being affected by the agreements. The results on the other combinations are presented in Table 4. Note that from the Vuong tests presented (Table 5), none of the liberal bilateral agreement combinations seem to fit the data better. 
TABLE 4

Cost Function: Alternative Scenarios

\begin{tabular}{|c|c|c|c|}
\hline & Scenario 5 & Scenario 6 & Scenario 7 \\
\hline Constant & $-.036(3.219)$ & $.281(.725)$ & $-.240(.776)$ \\
\hline$w_{L i}$ & $.389(.142)$ & $.401(.070)$ & $.374(.076)$ \\
\hline$Q_{i}$ & $1.016 \quad(.171)$ & $.983(.075)$ & $1.015(.056)$ \\
\hline $\mathrm{ASL}_{i}$ & -.340 & $-.340(.089)$ & $-.346(.082)$ \\
\hline $\mathrm{NET}_{i}$ & $-.381 \quad(.109)$ & $-.358(.085)$ & $-.354(.075)$ \\
\hline$T$ & $.135 \quad(.069)$ & $.124(.049)$ & $.100(.039)$ \\
\hline$e_{i}$ & $4.431 \quad(.500)$ & $4.550(.454)$ & $5.067(.674)$ \\
\hline SD of $\theta$ & $.301 \quad(.098)$ & $.316(.085)$ & $.407(.061)$ \\
\hline SD of error term & $.170 \quad(.054)$ & $.161(.049)$ & $.093(.050)$ \\
\hline
\end{tabular}

NOTE. - Standard deviation are in parentheses. Scenarios: (5) deregulation affects firms' behavior after 1985 for British Airways and KLM and after 1992 for the remaining companies, (6) deregulation affects firms' behavior after 1985 for British Airways, Sabena, and KLM and after 1992 for the remaining companies, and (7) deregulation affects firms' behavior after 1985 for British Airways, KLM, Lufthansa, and Sabena and after 1992 for the remaining companies. Alternative scenarios, namely, scenarios in which KLM or British Airways were excluded from the group of carriers participating to the liberal bilateral agreements from 1985, were also considered. Note that these scenarios could not be estimated because of convergence problems with the parameter $\mu$.

ticollinearity problems. ${ }^{17}$ In addition, a maximum likelihood test indicates that it is not possible to reject the model without capital against a model that includes it at any sensible confidence level. ${ }^{18}$ Moreover, scenarios $3^{\prime}$ and $4^{\prime}$ cannot be estimated because of convergence problems with the coefficient $\mu .{ }^{19}$ This indicates that the models are clearly misspecified, which suggests that the deregulatory measures included in the first EU package had no effect on firms' behavior, probably because of their limited scope (consistent with $\mathrm{Ng}$ and Seabright 2001).

For the remaining scenarios, the variables are significant and have the expected sign. Costs are increasing with wages and production, while they are decreasing with the size of the network and the average stage length. The alternative scenarios are tested against each other with the application of a test of nonnested hypothesis (see Vuong 1989). The test shows that scenario 4 is rejected against scenario 3 . This suggests that liberal bilateral agreements had a limited effect on firms' behavior, probably because they affected only a reduced number of routes. In addition, the results for scenario $3^{\prime \prime}$ are consistent with those for scenario 3 .

\footnotetext{
${ }^{17}$ This correlation problem is common to most empirical studies dealing with the estimation of short-run cost functions.

${ }^{18}$ We also estimated a long-run cost function in which capital was regarded as a variable input. Accordingly, a measure for the price of capital was computed from the companies' accounting data and included in the cost function. This variable was not significant at any confidence level.

${ }^{19}$ This indicates that $\mu$ and, accordingly, the internal cost of effort $\Psi(e)$, tend to infinity. If this was the case, firms would not undertake any effort, and equations (15) and (16) would be identical. In that case, a model with two separate periods would be clearly misspecified.
} 
TABLE 5

VuONG TESTS FOR TABLE 4

\begin{tabular}{lcccr}
\hline \hline & Scenario 4 & Scenario 5 & Scenario 6 & Scenario 7 \\
\hline Scenario 3 & 1.996 & 2.022 & 1.912 & 1.848 \\
Scenario 4 & $\ldots$ & -.136 & -.200 & -1.094 \\
Scenario 5 & $\ldots$ & $\ldots$. & -.235 & -.045 \\
Scenario 6 & $\ldots$ & $\ldots$. & $\ldots$ & .020 \\
\hline
\end{tabular}

NoTE. - The Vuong tests are performed for line $i$ against column $j$; that is, values for the Vuong test below -2 favor the model in column $j$ and above 2 favor the model in line $i$.

Scenarios 1 and 2 are rejected against scenario 3, which includes an inefficiency measure and assumes that deregulation affects firms' behavior after the introduction of the third EU package of deregulatory measures in 1992. Given that scenario 1 represents the standard approach proposed by the literature focusing on oligopolistic competition, its rejection supports the construction of models including these components and indicates that we have to be cautious when interpreting the results derived from other models. For instance, the results for scenario 3 suggest that the European airline industry is characterized by constant returns to scale, while scenarios 1 and 2 suggest the existence of increasing returns. ${ }^{20}$ In particular, rejection of scenario 2 shows the importance of accounting for the effects of deregulation on firms' technology and inefficiency.

Taken together, the two periods of regulation and deregulation allow us to identify the cost-reducing activity (namely, effort) in the model since a different cost structure (a different technology) for each period is considered. ${ }^{21}$ Hence, the technology and the technical inefficiency can be estimated. Accordingly, a direct measure of the effect of deregulation on costs can be quantified. From equation (6), a cost reduction ratio is given by $\varphi=$ $\left(C^{\mathrm{D}}(\cdot)-C^{\mathrm{R}}(\cdot)\right) / C^{\mathrm{R}}(\cdot)=\exp (-e)-1$. The cost reduction ratio for the average firm over the period of deregulation is $\varphi=-.234$, which implies that,

${ }^{20}$ Note, however, that only for scenario 1 can the hypothesis of constant returns to scale be rejected at the 5 percent level. This hypothesis for the airline industry is consistent with Caves, Christensen, and Diewert (1982) and Cornwell, Schmidt, and Sickles (1990), among others.

${ }^{21}$ We could measure the cost reduction after deregulation by estimating two cost functions (one pre- and one postderegulation) and comparing predicted costs. Our methodology, however, improves upon this alternative approach for two reasons. First, we estimate the coefficients describing the underlying technology with a larger sample. Note that, for instance, in order to estimate $\beta_{3}$, the alternative methodology would use information only for the period 1985-92, while with our methodology, we use information from the period 1985-99, at the cost of adding one more parameter. Second, the estimates of the underlying technology are needed to predict costs for the period 1993-99. Provided with these predicted costs, we can measure the cost reduction after deregulation. It is clear that including information on the period 1993-99 will increase the quality of our estimates of cost reduction. In addition, in Section V, we need to estimate marginal costs in order to evaluate competition. Marginal costs are defined as $\beta_{3} C_{i} / Q_{i}$. A biased measure of $\beta_{3}$ would lead to wrong conclusions about the evolution of pricecost margins after market deregulation. 
on average, the liberalization of the European airline industry led to a 23.4 percent cost decrease.

One could also compare the results regarding inefficiency obtained for a model with no effort, namely, scenario 2 , with those obtained with scenario 3 . We observe that inefficiency had been overestimated for all the companies. The average firm's inefficiency level is .215 under scenario 3 and .395 under scenario 2 . The two values are significantly different as measured by a $t$-test $\left(H_{0}: \theta_{(2)}-\theta_{(3)}=0\right)$ whose statistic is equal to 5.067.

In a second step, a precise evaluation of the nature of competition in the industry after deregulation can be obtained. We turn in the following section to the competitive aspect of our study.

\section{Evaluating Competition}

Having now the most adequate cost estimates in hand, we are capable of providing measures that characterize the degree of competition in the industry after the introduction of liberalization in 1992. ${ }^{22}$ Our results are compared with what would have been obtained if cost endogeneity had not been taken into account.

We define the pricing program of each airline carrier. Again, we need to distinguish the period of state regulation from the period of deregulation, during which firms are set free to choose prices in order to maximize their profit. Before deregulation, when firms are still state owned and regulated, the maximization program presented in (19) is irrelevant. During this period, prices result from bilateral agreements set by public authorities and are under the control of the firms only partially. We could think about alternative programs for this period, such as social welfare maximizing or monopoly pricing. This would, however, go beyond the scope of the paper since our intention is to focus on firms' competitive practices after deregulation.

In a deregulated environment, provided with the cost and demand functions, each firm solves the following program,

$$
\max _{p_{i}} \pi_{i}=q_{i}(\cdot) p_{i}-C^{\mathrm{D}}\left(\Phi\left(q_{i}(\cdot), \cdot\right), \omega_{i}, K_{i}, z_{i}, \theta_{i}, e^{\mathrm{D}}\right)-\Psi\left(e_{i}\right),
$$

where $p_{i}$ is the optimal price to be chosen.

\footnotetext{
${ }^{22}$ By estimating cost and demand functions, we are able to generate direct measures of the price-cost margins. This approach follows the spirit of Genesove and Mullin (1998), who show that direct estimations of the conduct parameter through the pricing rule may lead to significant underestimation of market power. Similarly, imposing a specific conduct and estimating costs may lead to over- or underestimation of costs when perfect competition or monopoly are assumed, respectively. On the contrary, estimates are quite insensitive to the assumed demand functional form.
} 
TABLE 6

Marginal Costs, Prices, and Margins

\begin{tabular}{lccccccc}
\hline \hline & \multicolumn{3}{c}{ SCEnario 1 } & & \multicolumn{3}{c}{ Scenario 3 } \\
\cline { 2 - 4 } \cline { 6 - 7 } & MC & Price $^{\mathrm{a}}$ & $M^{\mathrm{b}}$ & & MC & Price $^{\mathrm{a}}$ & $M^{\mathrm{b}}$ \\
\hline All carriers & .056 & .107 & .465 & & .065 & .107 & .376 \\
LBA carriers & .044 & .097 & .560 & & .051 & .097 & .486 \\
Non-LBA carriers & .062 & .111 & .418 & & .072 & .111 & .320 \\
\hline
\end{tabular}

NoTE. - All values for marginal costs and margins are significantly different from zero at the $1 \%$ level. LBA $=$ liberal bilateral agreements.

${ }^{\mathrm{a}}$ Observed values.

${ }^{\mathrm{b}} M=$ price-marginal cost margin as expressed in equation (20).

${ }^{c}$ Includes British Airways, KLM, and Lufthansa.

Accordingly, the first-order conditions for firm $i$ are given by

$$
\frac{p_{i}-\Phi^{\prime}\left(q_{i}(\cdot)\right) \mathrm{MC}_{i}^{\mathrm{D}}\left(\Phi\left(q_{i}(\cdot)\right)\right)}{p_{i}}=-\frac{q_{i}}{p_{i}} \frac{1}{\Delta_{i}},
$$

where

$$
\mathrm{MC}_{i}^{\mathrm{D}}(\cdot)=\frac{\partial C_{i}^{\mathrm{D}}}{\partial Q_{i}} \quad \text { and } \quad \Phi^{\prime}\left(q_{i}(\cdot)\right)=\frac{\partial Q_{i}}{\partial q_{i}} .
$$

The term $\Delta_{i}$ accounts for differences in price elasticities under different competitive situations. Using the estimates of the cost, capacity, and demand system obtained in the previous section, our aim is to evaluate the price-cost margins (expressed in the left-hand side of equation (19)) under the various scenarios under consideration and test these margins against those that could be obtained if carriers obeyed perfect Nash behavior, namely, when $\Delta_{i}=$ $\partial q_{i} / \partial p_{i}$. Thus, we can figure out whether different conclusions can be reached regarding carriers' competitive behavior if different scenarios are accounted for.

From the expressions of demand (11), capacity (10), and costs (17), the price first-order condition (under Nash behavior) can be rewritten as

$$
\frac{p_{i}-\left(\lambda_{1} Q_{i} / q_{i}\right) \mathrm{MC}_{i}(\cdot)}{p_{i}}=-\frac{q_{i}}{p_{i}} \frac{1}{\alpha_{1}} .
$$

Through the estimation of the cost function, marginal costs, $\mathrm{MC}_{i}$, can be easily recovered. Putting them together with our estimate of the capacitydemand elasticity $\lambda_{1}$, as well as the observed values for supply, demand, and prices, we are able to evaluate the weighted price-marginal cost margin, $M_{i}$, set by each carrier, defined as the left-hand side of equation (20). Table 6 presents the values obtained under scenarios 1 and 3 . Two interesting results are worth emphasizing. First, considering the traditional approach with no inefficiency and no effort, namely, scenario 1, would undervalue the average 
TABLE 7

Comparing Estimated Margins with Nash Behavior

\begin{tabular}{|c|c|c|c|c|c|}
\hline \multirow[b]{2}{*}{ Companies } & \multirow{2}{*}{$\begin{array}{c}\text { NASH } \\
\text { BEHAVIOR }\end{array}$} & \multicolumn{2}{|c|}{ SCENARIO 1} & \multicolumn{2}{|c|}{ SCENARIO 3} \\
\hline & & Estimated & $t$-Test $\mathrm{t}^{\mathrm{a}}$ & Estimated & $t$-Test $^{\mathrm{a}}$ \\
\hline All carriers & 1.213 & .465 & 6.459 & .376 & 7.180 \\
\hline LBA $_{\text {carriers }}{ }^{\mathrm{b}}$ & 2.077 & .560 & 11.189 & .486 & 11.822 \\
\hline Non-LBA carriers & .781 & .418 & 3.292 & .320 & 4.114 \\
\hline
\end{tabular}

marginal costs, $\mathrm{MC}$, and overestimate the margin, $M$, of the industry. Hence, the so-called traditional approach would undervalue the competition faced by the European airline carriers. The margins obtained under scenarios 1 and 3 are significantly different, as shown by a $t$-test $\left(H_{0}: M_{1}^{\mathrm{T}}-M_{3}^{\mathrm{T}}=0\right)^{23}$ whose statistic is equal to 2.359. Second, the companies that pioneered the liberalization process and signed liberal bilateral agreements (LBAs) with other EU countries and the United States obtain higher margins, even if these companies face lower marginal costs and propose lower prices.

Using our estimates for the demand equation, note that, as suggested by the right-hand side of equation (20), Nash behavior would entail an average margin $M_{\mathrm{N}}^{\mathrm{T}}$ for all the carriers in the sample equal to 1.213. Our price-marginal cost margin values obtained under scenarios 1 and 3 both lie below the Nash behavior margin $M_{\mathrm{N}}^{\mathrm{T}}$. A $t$-test $\left(H_{0}: M_{\mathrm{L}}^{\mathrm{T}}-M_{\mathrm{N}}^{\mathrm{T}}=0, l=1\right.$, 3) presented in Table 7 shows that neither of the two scenarios entails pure Nash behavior, although scenario 3 supports a more competitive behavior.

It is also worth distinguishing carriers that pioneered the liberalization process during the 1980s (LBA carriers) and those that switched to a competitive market after 1992. Table 6 suggests that British Airways, KLM, and Lufthansa were the operators setting the highest margins. This does not imply, however, that these firms have a less competitive behavior. Note that from the ratio $q_{i} / p_{i}$ evaluated at the average observation of the sample, it can be seen that the LBA companies meet demand on a more inelastic portion of the curve than other companies. ${ }^{24}$ Hence, pure Nash behavior for LBA companies entails a margin $M_{\mathrm{N}}^{\mathrm{LBA}}$ equal to 2.077, while for other companies, the margin $M_{\mathrm{N}}^{\mathrm{O}}$ is equal to .781 . Table 7 shows that the values of these margins under both scenarios 1 and 3 lie below the Nash behavior margins $M_{\mathrm{N}}^{\mathrm{LBA}}$ and $M_{\mathrm{N}}^{\mathrm{O}}$. The values of the $t$-tests $\left(H_{0}^{\mathrm{LBA}}: M_{\mathrm{L}}^{\mathrm{LBA}}-M_{\mathrm{N}}^{\mathrm{LBA}}=0\right.$ and $H_{0}^{\mathrm{O}}: M_{\mathrm{L}}^{\mathrm{O}}-$ $\left.M_{\mathrm{N}}^{\mathrm{O}}=0, l=1,3\right)$ suggest that neither of the two scenarios predicts Nash

\footnotetext{
${ }^{23}$ The term $M_{i}^{\mathrm{T}}$ denotes the average price-marginal cost margin under scenario $i$ when all the carriers of the database are considered.

${ }^{24}$ The $q / p$ ratio is more than three times higher on average for the LBA carriers.
} 
behavior for any set of companies. However, the other companies are closer to Nash behavior than the LBA carriers, which suggests that the latter have a more competitive behavior.

\section{CONCLUSIONS}

The results obtained in this paper have proved fruitful on both methodological and institutional sides. First, it has been shown that a cost-supplydemand structure that accounts for firms' technical inefficiency and costreducing activities fits the data better than the usual model proposed by the literature focusing on oligopolistic competition. Moreover, our application of this methodology to the airlines industry shows that the results obtained under the standard oligopoly model would be seriously biased and could lead to the wrong conclusions about efficiency and competition in the industry.

Second, it is suggested that the 1992 European deregulation package introduced a significant change in the behavior of airline carriers regarding efficiency improvement. We show that competition has increased significantly only after the introduction of the last package of deregulatory measures in 1992, since the liberal bilateral agreements had very limited effects and the 1987 EU package of deregulatory measures had no effect on firms' behavior. We also show that estimated competition is tougher than if obtained from a standard oligopoly model. This result is consistent with previous contributions in the same industry that take into account cost endogeneity in different manners.

\section{APPENDIX}

\section{Data Description and Construction of the Variables}

The data set has been constructed for the period 1985-99 from raw data included in Digest of Statistics (International Civil Aviation Organization 1985-89), World Air Transport Statistics (International Air Transport Association 1985-89), and Economic Outlook (Organisation for Economic Co-operation and Development 1985-89). The companies under study are the flag carriers from the largest European countries affected by the European liberalization process, namely, Alitalia, Air France, Air Portugal, British Airways, Iberia, KLM, Lufthansa, Sabena, and SAS.

The variables have been constructed as follows. In the cost function, costs $\left(C_{i}\right)$, production, $\left(Q_{i}\right)$, wages $\left(\omega_{L i}\right)$, capital $\left(K_{i}\right)$, and average stage length $\left(\mathrm{ASL}_{i}\right)$ correspond to total operating expenses (International Civil Aviation Organization 1985-89), seatkilometers available, flight crew salaries and expenses and maintenance and overhaul expenses over number of employees, fleet total number of seats, and total aircraft kilometers over total aircraft departures, respectively. With respect to total costs, companies report one single figure that corresponds to passenger, freight, and mail activities. The distribution of operations among these three activities can vary significantly among companies. However, it is easy to obtain information on the total number of tonne-kilometers flown that correspond to passengers (including baggage), freight, and mail. We multiply total costs reported by each company by the share of tonne-kilometers flown corresponding to passengers in order to compute our cost variable. The data needed to construct these variables have been retrieved from 
various issues of Digest of Statistics (International Civil Aviation Organization 1985-89), apart from number of employees that are published by International Air Transport Association. The term $\mathrm{NET}_{i}$ is constructed by the total number of route kilometers over which an airline operates (International Air Transport Association 1985-89). Finally, the price of materials $\left(\omega_{M i}\right)$ has been constructed as the average fuel prices for the carrier's home country and the Organisation for Economic Cooperation and Development (1985-89), weighted by the company's domestic and international operations, respectively (International Civil Aviation Organization 1985-89).

On the demand side, demand $\left(q_{i}\right)$ corresponds to passenger-kilometers flown, and firm $i$ 's weighted average price $\left(p_{i}\right)$ is measured as passenger revenues over passengerkilometers flown. Rivals' price $\left(p_{j}\right)$ is the average value for passenger revenues over passenger-kilometers of the remaining companies in the database. As carriers carry different quantities of passengers over different networks, rivals' prices are weighted by the total seat-kilometers available that they fly, which is a measure of firm size. Hence, rivals' average price $\left(p_{j}\right)$ gives more emphasis to carriers with a higher production, since these carriers meet firm $i$ on an higher number of routes and therefore exert a higher pressure on firm i's activity. All the data on demand are from International Civil Aviation Organization (1985-89). Consumption growth $\left(\mathrm{GCONS}_{i}\right.$ ) corresponds to domestic private consumption (Organisation for Economic Co-operation and Development 1985-89). Finally, $t$ the time trend, is equal to one in 1985 and incremented by one each year.

\section{REFERENCES}

Berechman, Joseph. 1993. Public Transit Economics and Deregulation Policy. Amsterdam: North Holland.

Borenstein, Severin. 1989. "Hubs and High Fares: Dominance and Market Power in the U.S. Airline Industry." Rand Journal of Economics 20: 344-65.

Caves, Douglas W., Laurits R. Christensen, and W. Erwin Diewert. 1982. "Multilateral Comparisons of Output, Input, and Productivity using Superlative Index Numbers." Economic Journal 92:73-86.

Cornwell, Christopher M., Peter Schmidt, and Robin C. Sickles. 1990. "Production Frontiers with Cross Sectional and Time Series Variation in Efficiency Levels." Journal of Econometrics 46:185-200.

Dalen, Dag M., and Andres Gomez-Lobo. 2003. "Regulatory Contracts and Cost Efficiency in the Norwegian Bus Industry: Do High-Powered Contracts Really Work?" Discussion Paper No. 6/2002. Norwegian School of Management, Oslo.

Gagnepain, Philippe, and Marc Ivaldi. 2002a. "Incentive Regulatory Policies: The Case of Public Transit Systems in France." Rand Journal of Economics 33:605-29.

_. 2002b. "Stochastic Frontiers and Asymmetric Information Models." Journal of Productivity Analysis 18:145-59.

Genesove, David, and Wallace P. Mullin. 1998. "Testing Static Oligopoly Models: Conduct and Cost in the Sugar Industry, 1890-1914." Rand Journal of Economics 29:355-77. 
International Air Transport Association. 1985-89. World Air Transport Statistics. Montreal: International Air Transport Association.

International Civil Aviation Organization. 1985-89. Digest of Statistics. Montreal: International Civil Aviation Organization.

Kumbhakar, Subal C., and C. A. Knox Lovell. 2000. Stochastic Frontier Analysis. Cambridge: Cambridge University Press.

Laffont, Jean-Jacques. 1994. "The New Theory of Regulation Ten Years After." Econometrica 62:507-37.

Laffont, Jean-Jacques, and Jean Tirole. 1993. A Theory of Incentives in Procurement and Regulation. Cambridge, Mass.: MIT Press.

Marín, Pedro L. 1995. "Competition in European Aviation: Pricing Policy and Market Structure." Journal of Industrial Economics 43:141-59. . 1998. "Productivity Differences in the Airline Industry: Partial Deregulation versus Short Run Protection.” International Journal of Industrial Organization 16:395-414.

Neven, Damien J., and Lars-Hendrik Röller. 1996. "Rent Sharing in the European Airline Industry." European Economic Review 40:933-40.

Neven, Damien J., Lars-Hendrik Röller, and Zhentang Zhang. 2001. "Endogenous Costs and Price-Cost Margins." DIW Discussion Paper No. 294. German Institute for Economic Research, Berlin.

Ng, Charles K., and Paul Seabright. 2001. "Competition, Privatization and Productive Efficiency: Evidence from the Airline Industry." Economic Journal 111:591-619.

Organisation for Economic Co-operation and Development. 1985-89. Economic Outlook. Paris: Organisation for Economic Co-operation and Development, Economics and Statistics Department.

Oum, Tae H., W. G. Waters II, and Jong-Say Yong. 1992. "Concepts of Price Elasticities of Transport Demand and Recent Empirical Estimates." Journal of Transport Economics and Policy 26:139-54.

Röller, Lars-Hendrik, and Robin C. Sickles. 2000. "Capacity and Product Market Competition: Measuring Market Power in a Puppy-Dog Industry." International Journal of Industrial Organization 18:845-65.

Vuong, Quang H. 1989. "Likelihood Ratio Tests for Model Selection and Non-nested Hypotheses." Econometrica 57:307-33. 